\title{
ANALISIS FAKTOR-FAKTOR YANG MEMPENGARUHI KEPUTUSAN PEMBELIAN VIA INTERNET PADA TOKO ONLINE
}

\author{
Mujiyana, Ingge Elissa \\ Jurusan Manajemen, Fakultas Ekonomi Universitas Gunadarma \\ Jl. Margonda Raya 100 Pondokcina - Depok Telp : 021-78881112 \\ mujiyana@staff.gunadarma.ac.id, iiisadate@yahoo.com
}

\begin{abstract}
Abstrak
Penelitian ini menganalisis pengaruh faktor-faktor yang mempengaruhi keputusan pembelian via internet pada Toko Online. Perkembangan teknologi informasi yang begitu pesat termasuk internet membawa dampak yang besar bagi segala aspek, tidak terkecuali perkembangan dunia bisnis dan pemasaran. Hal ini tidak aneh mengingat jumlah pengguna internet yang terus tumbuh pesat dapat menjadi sebuah pasar yang potensial untuk dimasuki para pebisnis. Di lain pihak, praktik e-commerce dan e-bisnis ternyata mempunyai banyak keuntungan baik bagi perusahaan atau pun konsumen.

Tujuan dari penelitian ini adalah untuk mengetahui adanya program periklanan, pemasaran melaui $E$-mail dan Kepercayaan konsumen terhadap pemrosesan informasi serta pengaruhnya terhadap Keputusan Pembelian produk-produk yang dijual di Toko Online. Penulisan ini menggunakan metode uji validitas dan relibilitas, uji normalitas, uji penyimpangan asumsi klasik seperti uji multikolinieritas dan uji heteroskedastisitas dan uji regresi linier berganda seperti uji t, uji f dan uji korelasi berganda dan determinasi, Analisis model persamaan struktural (structural equestion metode).

Hasil yang diperoleh dari penelitian ini adalah variabel program periklanan menunjukkan bahwa pengaruh yang besar terhadap variabel pemprosesan informasi dengan nilai 0,001 dan variabel pemprosesan informasi mempunyai pengaruh langsung terhadap keputusan pembelian dengan nilai 0,001. Mengindikasikan bahwa variabel independen berpengaruh signifikan secara positif pada tingkat signifikansi sebesar $5 \%$.
\end{abstract}

Kata Kunci : periklanan di Internet, keputusan pembelian, E-commerce

\begin{abstract}
This study analyzes the influence of factors that affect the purchasing decision via the internet at Online stores. The development of rapid information technologies including the internet brings great impact for all aspects, no exception to business and marketing world. This is no surprise given the number of internet users continues to grow by leaps and bounds can be a potential market to enter the business. On the other hand, the practice of e-commerce and e-business turned out to have a lot of advantages both for companies or consumers.

The purpose of this research is to know the existence of the program via E-mail advertising, marketing and consumer confidence as well as information processing to its influence on the decision to purchase products on sale in the Online store. Writing this using the method of test validity and reliability test, test the normality assumption deviation classics such as relevant test and heteroskedastisitas test and multiple linear regression tests such as $t$-test, $f$-test and test multiple correlation and determination, structural equation model Analysis (structural equestion metode).

The results obtained from this research is variable advertising program indicate that a major effect of the variable with a value of 0.001 information processing and information processing variables have a direct influence on purchasing decisions with a value of 0.001. Indicates that the independent variable effect significantly positively on the level of significance of 5\%.
\end{abstract}

Keywords : advertising on the internet, purchasing decisions, E-Commerce

\section{PENDAHULUAN \\ Latar Belakang}

Dengan adanya internet sebuah paradigm baru ekonomi telah lahir. Dunia maya terbentuk seiring dengan berkembangnya teknologi internet, tidak terkecuali perkembangan dunia bisnis dan pemasaran. Sekarang sudah banyak orang yang memanfaatkan internet sebagai media pemasaran dan bisnis. Hal ini tidak aneh 
mengingat jumlah pengguna internet yang terus bertumbuh pesat dapat menjadi sebuah pasar yang potensial untuk dimasuki para pebisnis. Di lain pihak, praktik $e$ commerce dan e-bisnis ternyata mempunyai banyak keuntungan baik bagi perusahaan ataupun konsumen.

E-commerce lebih dari sekedar membeli dan menjual produk secara online. E-commerce meliputi seluruh proses dari pengembangan, pemasaran, penjualan, pengiriman, pelayanan, dan pembayaran para pelanggan, dengan dukungan dari jaringan para mitra bisnis di seluruh dunia. Sistem e-commerce sangat bergantung pada sumber daya internet dan banyak teknologi informasi lainnya untuk mendukung setiap proses ini.

Selain alasan untuk pengembangan bisnis, penggunaan sumber daya internet dikarenakan jumlah potensial dari pengguna internet di seluruh dunia yang dari tahun ke tahun mengalami peningkatan.

Dari tahun 2000-2011 terlihat pada data di atas bahwa pertumbuhan pengguna internet di Dunia mengalami pertumbuhan sebesar $528,1 \%$. Dari jumlah penduduk di Dunia yaitu 6.930.055.154 sebesar 32,7\% telah menggunakan internet, ini berarti sebagian orang di dunia sudah mengenal internet atau sudah menjadi gaya hidup sehari-hari.

Apabila dilihat dari data tersebut dapat disimpulkan bahwa pengguna internet baik secara global maupun nasional mengalami peningkatan yang cukup pesat. Hal ini jelas menjadi sebuah potensi bisnis yang sangat menjajikan.

Tabel 1 Data Pengguna Internet di Dunia

\begin{tabular}{|c|c|c|c|c|c|c|}
\hline \multicolumn{7}{|c|}{$\begin{array}{l}\text { WORLD INTERNET USAGE AND POPULATION STATISTICS } \\
\text { December } 31,2011\end{array}$} \\
\hline World Regions & $\begin{array}{l}\text { Populetion } \\
\text { (2011 Eat) }\end{array}$ & $\begin{array}{l}\text { Intemet Users } \\
\text { Dec J1, } 2000\end{array}$ & $\begin{array}{l}\text { Internet Unens } \\
\text { Latest Data }\end{array}$ & $\begin{array}{c}\text { Penetration } \\
\text { (S. Population) }\end{array}$ & $\begin{array}{c}\text { Growth } \\
2003.2011\end{array}$ & $\begin{array}{l}\text { Users } 5 \\
\text { of Table } \\
\end{array}$ \\
\hline Africa & $1,037,424,058$ & \begin{tabular}{|r|}
$, 514,400$ \\
\end{tabular} & $199,875,242$ & $13.5 \mathrm{~s}$ & $2565.4 \%$ & $62 \mathrm{~N}$ \\
\hline Asla & $3,879,740.877$ & $114,304,000$ & $1,016,799,076$ & 26.25 & $7896 \%$ & $418 \%$ \\
\hline Eurepe & $816,426,346$ & $105,096,093$ & $500, m 3,605$ & $61.3 \%$ & $376.4 \%$ & $22.1 \%$ \\
\hline Midtle Eost & 216.258 .843 & $3.234,800$ & $n, 020,98$ & $35.6 \%$ & $2.248 \%$ & $34 \%$ \\
\hline Norh America & $347,234,870$ & $109,096,000$ & $273,067,546$ & $78.6 \mathrm{~s}$ & $1526 \%$ & $12.0 \mathrm{~s}$ \\
\hline Latin America / Catibs & $597,283,165$ & 18.068 .919 & $235,819,740$ & $395 \%$ & $1,205.1 \%$ & 10.48 \\
\hline Oceania / Australla & $35,426,995$ & $7,620,400$ & $23,927,457$ & 67.55 & $2140 \%$ & $1,1 \mathrm{~s}$ \\
\hline WORLO TOTAL & $6,930,055,154$ & $360,985,492$ & $2,267,233,742$ & $32.7 \mathrm{~s}$ & 528.15 & 100.05 \\
\hline
\end{tabular}

Sumber : $\underline{\text { www.internetworldstats.com }}$

Tabel 2 Data Pengguna Internet di Asia

\begin{tabular}{|c|c|c|c|c|c|c|}
\hline AstA & $\begin{array}{l}\text { Populatioe } \\
\text { (2011 fst) }\end{array}$ & $\begin{array}{l}\text { Intemet Uiens, } \\
\text { (Year 2000) }\end{array}$ & 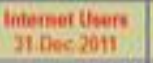 & $\begin{array}{l}\text { Penetration } \\
\text { (S. Pepsiation) }\end{array}$ & $\begin{array}{l}\text { Usen: } \\
\text { SAsia }\end{array}$ & $\begin{array}{l}\text { Facebook } \\
\text { Ji Mar .012 }\end{array}$ \\
\hline Afganistan & 20.05 .392 & 1,000 & $1,236,470$ & $42 \mathrm{~s}$ & $01 \%$ & 287.440 \\
\hline Armenia & 2.567 .975 & 39.000 & $1,396.5 \%$ & 4715 & $0.1 \mathrm{~s}$ & 202.700 \\
\hline Areibalian & $1323 n$ & 12,000 & 3.609 .000 & 4415 & $04 \mathrm{~s}$ & 702.000 \\
\hline Dangladeah & 14.570 .535 & 100,000 & $5.501,600$ & $35 \mathrm{~s}$ & $0.5 \leqslant$ & 2590.600 \\
\hline Ehutas & 700.427 & 60 & $90.17 t$ & $139 \leqslant$ & $0.0 \mathrm{~s}$ & 6.660 \\
\hline PloueciDarusalen & 401.090 & 30.060 & 318.900 & $704 \mathrm{~s}$ & $0.0 \mathrm{~s}$ & 29060 \\
\hline Camborlia & 14.701 .717 & 6.000 & 491,460 & 315 & $00 \%$ & 449.160 \\
\hline CMina ${ }^{*}$ & $1,3 \times 6710.015$ & $22,500,000$ & $513,100,000$ & $304 \leqslant$ & 5055 & 447,460 \\
\hline Georpia & 4.54074 & 20,000 & $1,300,000$ & 2035 & 0.15 & $90 r 620$ \\
\hline Heng Kong * & $7,122.500$ & 2.203000 & $4,894,913$ & $607 \leqslant$ & 058 & 3752.160 \\
\hline India & $1,469,172,906$ & $5,000,000$ & $121,000,000$ & $102 \mathrm{~s}$ & 1105 & $45,048.100$ \\
\hline Indonesia & $245,613,043$ & 2000,000 & $\$ 5,000,000$ & $n+15$ & 548 & 43523.740 \\
\hline Jopan & $126.476,664$ & $47,060,000$ & $101,228,736$ & $000 \mathrm{~s}$ & $100 \mathrm{~s}$ & $7,64,120$ \\
\hline Karakhstan & $15,522,373$ & 70000 & $9,448,965$ & $35.1 \%$ & $0.5 \%$ & 452200 \\
\hline Korea, North & $24,457,492$ & $\pi$ & $\Rightarrow$ & $\pi$ & - & n'a \\
\hline Korea, South & 4.744.657 & 19.060 .000 & $40,329,6 \omega$ & $027 \mathrm{~s}$ & $40 \mathrm{~s}$ & 6.376 .160 \\
\hline Kyrmystan & $5.587,443$ & 51,000 & $2,194,400$ & 3035 & 028 & 76,300 \\
\hline
\end{tabular}


Sebagian dari pengguna internet Indonesia dan di luar negeri, telah melakukan pembelian online. Tren belanja online mulai diminati karena proses keputusan belanja online tidak serumit keputusan pembelian offline. Belanja online memang memudahkan dan menghemat waktu, menghemat biaya dibandingkan belanja tradisional. Proses keputusan belanja online adalah pencarian informasi, membandingkan alternatif yang ada, dan pengambilan keputusan. Pada tahap pencarian informasi, konsumen akan mencari referensi secara online dari manapun (seperti search engine atau Toko Online). Informasi yang dicari adalah berupa opini dari orang lain yang sudah mendapatkan manfaat dari produk yang dibeli.

Tujuan Penelitian ini yaitu :

1. Untuk menganalisis program periklanan, pemasaran melalui e-mail, serta tingkat kepercayaan secara signifikan mempengaruhi pemrosesan informasi periklanan oleh konsumen di Toko Online.

2. Untuk menganalisispemasaran melalui email, pemprosesan informasi, serta tingkat kepercayaan konsumen yangsecara signifikan mempengaruhi keputusan pembelian konsumen di Toko Online.

3. Untuk menganalisis variable kepercayaan konsumen dan pemasaran melalui e-mail secara signifikan mempengaruhi keputusan pembelian konsumen baik secara langsung maupun melalui tahap pemrosesan informasi periklanan oleh pengguna internet di Toko Online.

\section{TELAAH PUSTAKA \\ Pengertian Pemasaran}

Pemasaran adalah salah satu kegiatan dalam perekonomian yang membantu dalam menciptakan nilai ekonomi yang menentukan harga barang dan jasa. Faktor penting dalam menciptakan nilai tersebut adalah produksi, pemasaran dan konsumsi. Pemasaran menjadi penghubung antara kegiatan produksi dan konsumsi. Menurut Assauri (2004), "Pemasaran adalah kegiatan manusia yang diarahkan untuk memenuhi dan memuaskan kebutuhan dan keinginan melalui proses pertukaran". Menurut Kennedy (2006), "Pemasaran adalah sekumpulan rancangan kegiatan yang saling terkait untuk mengenali dan mengembangkan, mendistribusikan, mempromosikan, serta menetapkan harga yang tepat dari sebuah produk dan layanan untuk mencapai kepuasan dari konsumen yang bertujuan untuk menghasilkan keuntungan". Menurut Khotler (2005), "Pemasaran merupakan suatu proses sosial dan manajerial yang membuat individu dan kelompok dapat memperoleh apa yang mereka butuhkan sereta inginkan dalam penciptaan dan timbal balik produk dan nilai dengan orang lain".Sedangkan Saladin (2003), "Pemasaran merupakan suatu sistem total dari kegiatan bisnis yang dirancang untuk merencanakan, menentukan harga, promosi dan mendistribusikan barang yang dapat memuaskan keinginan setra mencapai pasar sasaran serta tujuan perusahaan".

\section{Bauran Komunikasi Pemasaran}

Menurut Kotler bauran komunikasi pemasaran (disebut juga bauran promosi) terdiri dari lima cara komunikasi utama yaitu :

\section{Advertising}

Peranan periklanan dalam pemasaran sangatlah penting, yakni untuk membangun kesadaran (awareness) terhadap keberadaan produk atau jasa yang ditawarkan, untuk menambah pengetahuan konsumen tentang produk atau jasa yang ditawarkan, untuk membujuk calon pelanggan untuk membeli atau menggunakan produk atau jasa tersebut. Sedangkan, tujuan utama dari periklanan adalah memberikan informasi secara luas kepada konsumen tentang barang atau jasa yang ditawarkan suatu perusahaan. Adapun tujuan Advertising diantaranya :

a. Untuk memberikan Informasi atas produk atau jasa yang ditawarkan untuk menciptakan permintaan atas produk tersebut.

b. Untuk mempertahankan calon pelanggan yang setia dengan membujuk pelanggan agar tetap membeli. 
c. Untuk membujuk calon pelanggan dimana iklan menjadi penting dalam persaingan dimana sasaran perusahaan menciptakan permintaan selektif akan merek tertentu.

d. Untuk menarik pelanggan baru, dengan menarik arus kas pembelian kearah produk yang diiklankan perusahaan dan menggantikan tempat para pelanggan yang pindah ke produk pesaing serta memperluas pasar.

\section{Promosi Penjualan}

Promosi merupakan suatu aktivitas dan materi yang dalam aplikasinya menggunakan teknik, dibawah pengendalian penjual/produsen, yang dapat mengkomunikasikan informasi persuasif yang menarik tentang produk yang ditawarkan oleh penjual/produsen, baik secara langsung maupun melalui pihak yang dapat mempengaruhi pembelian. Tujuan kegiatan promosi antara lain:

a. Mengidentifikasi dan menarik konsumen baru

b. Mengkomunikasikan produk baru

c. Meningkatkan jumlah konsumen untuk produk yang telah dikenal secara luas

d. Menginformasikan kepada konsumen tentang peningkatan kualitas produk

e. Mengajak konsumen untuk mendatangi tempat penjualan produk

f. Memotivasi konsumen agar memilih atau membeli suatu produk

\section{Publicity}

Publicity atau publisitas merupakan kiat pemasaran, dimana perusahaan tidak hanya berhubungan dengan kumpulan publik yang lebih besar. Adapun Fungsi utama dari Publicity meliputi : a) Membangun image (citra), baik image perusahaan maupun image produk. b) Mendukung aktivitas komunikasi. c) Mengatasi isu atau permasalahan yang ada. d) Memperkuat posisi perusahaan. e) Cukup mengadakan Lounching untuk produk atau jasa baru.

\section{Personal Selling}

Menurut Retno Dewanti (2008), "Penjualan Perorangan (personal selling) adalah kontak langsung antara perusahaan dengan para konsumennya melalui wiraniaga yang terlatih untuk membangun hubungannya dengan para pelanggan”. Personal Selling dapat juga dikatakan sebagai improvisasi dan penjualan dengan menggunakan komunikasi person to person. Personal Selling biasanya dilaksanakan oleh sales bawah naungan manajer penjualan yang mempromosikan produk secara langsung pada pasar sasaran, bentuk kegiatan personal selling yaitu : Door to door sellin, Mail Order, Telephon selling, Direct selling

\section{Direct Selling}

Direct Selling atau direct marketing adalah bagian dari program marketing communication, dimana direct marketing dilakukan sebagai cara untuk bertemu oleh konsumen setelah muncul respon dari pasar atas informasi produk yang telah disabarkan kepada konsumen melalui media (iklan disurat kabat, televisi, radio, majalah, imnternet atau media masa lainnya). Dalam Direct Marketing pasar tidak dapat diraih jika hanya menggunakan salah satu cara, tetapi strategi pemasaran yang efektif adalah memasuki pasar dengan berbagai cara media, malalui perhitungan yang tepat.

\section{Pengertian Internet}

Internet adalah singkatan dari interconnection networking yang secara sederhana bisa diartikan sebagai a global network of computer networks ( Randal dan Latulipe, 2005). Pada era siber internet memiliki akselerasi hyperekponensial yang sulit dibayangkan, sehingga membentuk sebuah komunitas yang memanfaatkan internet secara maksimum untuk kepentingan hidupnya salah satunya adalah untuk kepentingan berkomunikasi tanpa batas ras, bangsa, geografi kelas dan batasan-batasan lainya. 
Menurut Darmawan (2004), saat ini sebagian besar orang beranggapan periklanan diinternet hanyalah memindahkan media tempat beriklan dari media cetak ke media elektronik biasa ke media online yang lebih interaktif. Para pemilik iklan atau situs ini kebanyakan masih memiliki pikiran bahwa beriklan diinternet akan sama hasilnya dengan beriklan dimedia massa. Banyak perusahaan diindonesia yang belum memahami pentingnya internet sebagai sarana promosi dan perusahaan mereka.

\section{Konsep Website}

Perberkembang penggunaan website saat ini merupakan kabar yang menggembirakan bagi banyak praktisi IT. Situs website banyak diperlukan untuk berbagai kepentingan berkaitan dengan penyampaian informasi mulai dari perusahaan besar, perusahaan kecil, lembaga pemerintahan, pendidikan, dunia hiburan dan masih banyak lagi.Website merupakan sarana yang efektif untuk melakukan promosi produk dan jasa sehinggan cukup banyak perusahaan penjualan barang dan jasa yang membuat website atau dapat disebut dengan istilah ecommerce. Website juga terbukti menjadi media informasi yang diminati selain media informasi lainya. Hal ini disebabkan karena sifat website yang interaktif, menarik, jangkauan global dan informasinya yang $u p$ to date.

Dari segi bahasa, toko online berasal dari dua suku kata, Toko dan Online. Menurut Kamus Besar Bahasa Indonesia, toko berarti sebuah tempat atau bangunan permanen untuk menjual barangbarang (makanan, minuman, dan sebagainya). Sedangkan online yang terjemahan bahasa indonesianya adalah dalam jaringan atau disingkat daring menurut Wikipedia adalah keadaan di saat seseorang terhubung ke dalam suatu jaringan ataupun sistem yang lebih besar. Jadi berangkat dari dua pengertian secara bahasa tersebut kita dapat mengartikan toko online sebagai tempat terjadinya aktifitas perdagangan atau jual beli barang yang terhubung ke dalam suatu jaringan dalam hal ini jaringan internet.

\section{Belanja Online}

Belanja online (online shopping) adalah proses dimana konsumen secara langsung membeli barang-barang, jasa dan lain lain dari seorang penjual secara interaktif dan real-time tanpa suatu media perantara melalui Internet. Melalui belanja lewat Internet seorang pembeli bisa melihat terlebih dahulu barang dan jasa yang hendak ia belanjakan melalui web yang dipromosikan oleh penjual.Kegiatan belanja online ini merupakan bentuk komunikasi baru yang tidak memerlukan komunikasi tatap muka secara langsung, melainkan dapat dilakukan secara terpisah dari dan ke seluruh dunia melalui media notebook, komputer, ataupun handphone yang tersambung dengan layanan akses Internet. Belanja online adalah salah satu bentuk perdagangan elektronik yang digunakan untuk kegiatan transaksi penjual ke penjual ataupun penjual ke konsumen. (Cipta Halim "berbelanja Smart dan Membuka gerai gaul" 2010) belanja online pertama kali dilakukan di Inggris pada tahun 1979 oleh Michael Aldrich dari Redifon Computers.

\section{Pengertian Perdagangan Elektronik (E- Commerce)}

Menurut M.Suyanto (2003), "Penggolongan E-Commerce yang lazim dilakukan orang ialah berdasar sifat transaksinya. Tipe - tipe berikut segera bisa dibedakan :

a. Business-to-business (B2B), kebanyakan E-commerce yang diterapkan saat ini merupakan tipe B2B.E-Commerce tipr ini meliputi transaksi IOS yang digambarkan sereta transaksi antar organisasi yang dilakukan di Electronic Market. Contohnya, Wal-mart dengan Warner Lambert.

b. Business-to-consummer (B2C), ini merupakan transaksi eceran dengan konsumen perorangan.

c. Consummer-to-consummer (C2C), dalam kategori ini seorang konsumen menjual langsung ke konsumen lainnya. Contohnya eBay.com yaitu perusahaan lelang.

d. Consummer-to-Business (C2B), yang termasuk kedalam kategori ini adalah perseorangan yang menjual produk atau 
layanan ke organisasi dan perorangan yang mencari penjual, berinteraksi dengan mereka dan menyepakati suatu interaksi.

e. NON Business E-Commerce, dewasa ini semakin banyak lembaga nonbisnis seperti lembaga akademis, organisasi nirlaba, organisasi keagamaan, organisasi sosial, dan lembaga pemerintahan yang menggunakan media e-commerce untuk mengurangi biaya atau untuk meningkatkan operasi dan layanan publik.

f. Intrabusinnes (Organizational) $e$ Commerce, yang termasuk dalam kategori ini adalah semua aktivitas intern organisasi, biasanya dijalankan diinternet yang melibatkan pertukaran barang, jasa, atau informasi.

\section{Pengertian Promosi}

Basu Swastha

mendefinisikan,"Promosi adalah arus informasi atau persuasi atau arah yang dibuat untuk mengarahkan seseorang atau orhanisasi kepada tindakan menciptakan pertukaran dalam pemasaran". Saladin (2003) mendefinisikan "Promosi adalah suatu komunikasi informasi penjual dan pembeli yang bertujuan untuk menambah sikap dan tingkah laku pembeli, yang tadinya tidak mengenal menjadi mengenal sehingga menjadi pembeli dan tetap mengingat produk tersebut ". Dari beberapa definisi tersebut, kesimpulannya adalah promosi dilakukan untuk mengarahkan dan mendorong seorang konsumen untuk melaksanakan pembelian barang atau jasa, yang merupakan salah satu aspek penting dalam kegiatan pemasaran dan sering dikatakan sebagai ujung tombak pemasaran.

\section{Pemasaran Melalui E-mail}

Dalam mempromosikan bisnis melalui e-mail, perlu dicantumkan alamat website atau link Affiliate agar atau para pengguna internet mengkliknya dan membuka website yang dicantumkan, promosi melalui E-Mail dapat dilakukan pada :

1. Content pada E-mail yang terdiri atas subject (judul) dan isi e-mail

2. Signature, pada Signature kita dapat mencantumkan link website disertai deskripsi singkat mengenai website bisnis internet

3. Response e-mail, umumnya digunakan sebagai konfirmasi kepada pengirim email bahwa yang ia kirim sudah diterima dan akan dijawab kemudian, atau sebagai informasi bahwa kita sedang berada diluar kantor atau sedanga berlibur sehingga belum bisa membahas e-mail tersebut dalam jangka waktu tertentu.

\section{Evaluasi Efektifitas Periklanan pada $\boldsymbol{E}$ - Commerce}

Melakukan penilaian terhadap iklan diinternet lebih sulit dibanding melakukan hal yang sama untuk iklan yang konvensional. Alasan utamanya adalah sulitnya mengukur hasil pengiklanan tersebut. Ada sejumlah metode untuk mengukur iklan terbagi menjadi 2 yaitu :

1. Evaluasi Efektifitas Iklan di Internet Berdasarkan Biaya- Manfaat, dengan melakukan analisis cost benefit dan pricing ads. Didalam penyeleseaian analisis ini terdapat beberapa model atau bentuk diantaranya a) Model berdasarkan CPM (Cost Per Thousand),biaya perseribu impresi. b) Model Click-Though, upaya untuk mengembangkan cara pengenaan biaya periklanan web secara lebih accountable. c) Model Interaktivitas. d) Model Pembelian Aktual.

2. Evaluasi Iklan Diinternet model Konsumen yang terdiri dari : a) Evaluasi Rekognisi dan Recall. b) Evaluasi Komunikasi. c) Evaluasi Persuasi

\section{Kepercayaan}

Ketika seorang berbelanja online, hal utama yang menjadi pertimbangan seorang pembeli adalah apakah mereka percaya kepada website yang menyediakan online shopping dan penjual online pada website. Kepercayaan pembeli terhadap website online shopping terletak pada popularitas website online shopping. Semakin popularitas suatu website, maka pembeli lebih yakin dan percaya terhadap reliabilitas website. Selanjutnya, kepercayaan pembeli terhadap penjual online terkait dengan keandalan penjual online dalam menjamin 
keamanan bertransaksi dan meyakinkan transaksi akan diproses setelah pembayaran dilakukan oleh pembeli. Kendala ini terkait dengan keberadaan penjual online. Semakin berkembangnya teknologi, semakin berkembang pula modus penipuanberbasis teknologi pada online shopping. Pada situssitus online shopping, tidak sedikit penjual online fiktif yang memasarkan produk fiktif juga. Seorang pembeli harus terlebih dahulu untuk mengecek keberadaan penjual online. Biasanya pada situs online shopping, situs akan menampilkaninformasi tentang penjual-penjual yang "lapaknya" sering diakses oleh orang. Pembeli dapat memanfaatkan informasi ini ketika akan membeli online.

\section{Keputusan Pembelian}

Secara umum, keputusan adalah pemilihan dari dua atau lebih alternatif pilihan. Dengan kata lain untuk membuat keputusan harus terdapat alternatif pilihan. Sebaliknya jika konsumen tidak memiliki alternatif untuk memilih maka tidakdapat dikategorikan sebagai pengambilan keputusan. Tidak semua konsumen dalam mengambilkeputusan memerlukan tingkat pencarian informasi yang sama. Jika dalam pengambilankeputusan memerlukan usaha yang besar, maka konsumen perlu meluangkan waktu untukmelalukan proses keputusan. Sebaliknya untuk pembelian yang sifatnya rutin cenderungmerupakan peristiwa yang monoton dan menunjukkan berkurangnya tingkat kesenangan.Terdapat tiga tingkat pengambilan keputusan oleh konsumen dari usaha yang paling tinggi keusaha yang paling rendah, yaitu: extensive problem solving, limited problem solving danroutinized response behavior

\section{METODE PENELITIAN}

Dalam penelitian ini, populasi yang digunakan orang yang pernah melakukan pembelian pada toko online yang ada, karena populasi yang digunakan adalah seluruh yang pernah melakukan pembelian pada toko online jumlahnya sangat banyak (tersebar dan sulit diketahui secara pasti), maka dilakukan pengambilan sampel untuk penelitian ini. Metode analisis data yang digunakan dalam penelitian ini menggunakan regresi berganda dimana sebelumnya diolah dengan menggunakan skala Likert dari pertanyaan yang diberikan kepada responden (Sugiyono,2005).

\section{Analisis Deskriptif}

Analisis deskriptif digunakan untuk memberikan deskripsi suatu data yang dilihat dari rata-rata, standar deviasi, modus, maksimum-minimun. Hal ini perlu dilakukan untuk melihat gambaran keseluruhan dari sampel yang berhasil dikumpulkan dan memenuhi syarat untuk dijadikan sampel penelitian dengan menggunakan tabulasi data.

\section{Analisis Kuantitatif}

Dalam penelitian ini, karena jenis data yang digunakan adalah data kualitatif, maka analisis kuantitatif dilakukan dengan cara mengkuantifikasi data-data penelitian ke dalam bentuk angka-angka dengan menggunakan skala rasio (ratio scale) dan skala likert 7 poin (7-point likert scale).

\section{Tahapan Permodelan dan Analisis Persamaan Struktural}

Menurut Imam Ghozali (2007), Structural Equetion Modelling (SEM) digambarkan oleh hubungan antara variabel lantent yang ditandai dengan garis dengan satu anak panah yang menhubungkan kausalitas ( regresi ) dan garis dengan dua anak panah yang menggambarkan hubungan korelasi atau kovarian.

Tabel 3 Indeks Goodness of Fit Model

\begin{tabular}{ll}
$\begin{array}{l}\text { Goodness of Fit } \\
\text { Index }\end{array}$ & Cut-off Value \\
\hline $\begin{array}{l}\text { Chi-Square }\left(\chi^{2}\right) \\
\text { Degree of Freedom } \\
\text { (df) }\end{array}$ & $\begin{array}{l}\text { Diharapkan kecil } \\
\text { Positif }\end{array}$ \\
\hline Significance & $\geq 0,05$ \\
Probability (P- & \\
Value) & $\leq 0,05$ \\
RMSEA & $\geq 0,90$ \\
GFI & $\geq 0,90$ \\
AGFI & $\leq 2,00$ \\
CMIN/DF & $\geq 0,95$ \\
TLI & $\geq 0,94$ \\
CFI & \\
\hline
\end{tabular}


Hipotesis yang diuji adalah :

H1 : Adanya pengaruh program periklanan di internet, pemasaran melalui email, serta tingkat kepercayaan konsumen secara signifikan mempengaruhi terhadap pemrosesan informasi periklanan.

H2 : Adanya pengaruh pemasaranmelalui e-mail dan tingkat kepercayaan secara signifikan mempengaruhi terhadap keputusan pembelian melalui e-mail.

H3 : Adanya pengaruh pemprosesan informasi periklanan secara signifikan terhadap keputusan pembelian melalui internet.

\section{PEMBAHASAN}

\section{Karakteristik Responden}

Karakteristik identitas responden adalah profil terhadap obyek penelitian yang dapat memberikan interpretasi terhadap hasil penelitian mengenai faktorfaktor yang mempengaruhi keputusan pembelian via internet pada Toko Online. Dimana untuk mengimplementasikan hal tersebut, maka responden dalam penelitian ini adalah seluruh pelanggan pelanggan Toko Online yakni ditetapkan sebanyak 150 orang responden.

\section{Evaluasi Kriteria Goodness of Fit}

Evaluasi kriteria goodness of fit terhadap model yang dihasilkan secara lengkap dapat dilakukan sebagai berikut: Evaluasi normalitas data dilakukan dengan menggunakan kriteria critical ratio skewness value sebesar \pm 2.58 pada tingkat signifikansi 0,01 (1\%). Data dikatakan berdistribusi normal jika nilai critical ratio skewness value di bawah harga mutlak 2.58 (Ghozali, 2008).

Tabel 4 Asumsi Normalitas

\begin{tabular}{|l|rrrrrr|}
\hline Variable & $\min$ & $\max$ & Skew & c.r. & kurtosis & c.r. \\
\hline kp4 & 2.000 & 7.000 & -1.077 & -5.386 & 1.134 & 2.834 \\
kp2 & 1.000 & 7.000 & -1.359 & -6.795 & 3.884 & 9.710 \\
pi1 & 1.000 & 7.000 & -1.312 & -6.562 & 1.866 & 4.664 \\
pi3 & 1.000 & 7.000 & -1.014 & -5.071 & .776 & $\mathbf{1 . 9 4 1}$ \\
em1 & 2.000 & 7.000 & -.750 & -3.748 & .147 & $\mathbf{. 3 6 9}$ \\
em3 & 2.000 & 7.000 & -.523 & -2.614 & -.405 & $\mathbf{- 1 . 0 1 2}$ \\
kpc8 & 1.000 & 7.000 & -.998 & -4.990 & 1.199 & 2.996 \\
kpc7 & 3.000 & 7.000 & -.477 & -2.387 & -.514 & $\mathbf{- 1 . 2 8 6}$ \\
kpc6 & 1.000 & 7.000 & -.946 & -4.730 & 1.041 & 2.603 \\
kpc5 & 3.000 & 7.000 & -.463 & -2.315 & -.705 & $\mathbf{- 1 . 7 6 3}$ \\
kpc4 & 1.000 & 7.000 & -1.116 & -5.580 & 1.732 & 4.330 \\
kpc3 & 3.000 & 7.000 & -.535 & -2.676 & -.557 & $\mathbf{- 1 . 3 9 3}$ \\
kpc2 & 1.000 & 7.000 & -1.627 & -8.135 & 4.854 & 12.134 \\
kpc1 & 3.000 & 7.000 & -.960 & -4.800 & .748 & $\mathbf{1 . 8 7 1}$ \\
pp1 & 1.000 & 7.000 & -.882 & -4.411 & .547 & $\mathbf{1 . 3 6 7}$ \\
pp2 & 1.000 & 7.000 & -.941 & -4.703 & 1.289 & 3.222 \\
Multivariate & & & & & 81.214 & 20.722 \\
\hline
\end{tabular}

Sumber: Data primer diolah, 2011 
Berdasarkan hasil di atas dapat dilihat bahwa angka nilai skewness value dan kurtosis value variabel pi3, em1,em3, kpc7, kpc5, kpc3, kpc1, pp1, menunjukkan distribusi normal karena nilainya dibawah \pm 2.58, yaitu 1.941, 0.369, -1.012, -1.286, $1.763,-1.393,1.871,1.367$, yang lainnya tidak terdistribusi normal. Oleh karena nilai multivariate memberikan nilai diatas \pm 2.58 dapat dikatakan secara multivariate data berdistribusi tidak normal.

Pengujian Hipotesis pertama dengan menggunakan SEM dilakukan untuk membuktikan pengaruh program periklanan di internet, pemasaran melalui email, dan kepercayaan terhadap pemprosesan informasi. Berikut deskripsi hasil pengujian selengkapnya disajikan pada tabel dibawah ini :

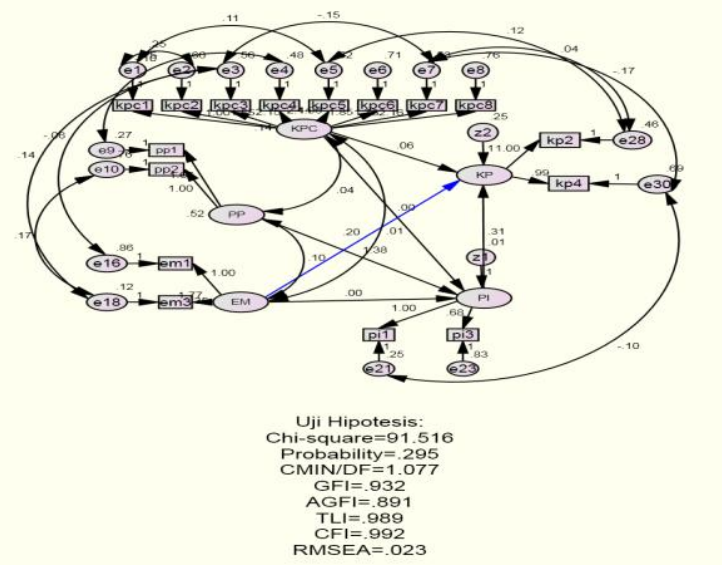

Gambar 1Output AMOS

Tabel 5 Hasil Perhitungan Indeks Goodness-of-fit model

\begin{tabular}{cccc}
\hline $\begin{array}{c}\text { Goodness-Of-Fit } \\
\text { (GOF) }\end{array}$ & Hasil Analisis & Cut Off Value & Evaluasi Model \\
\hline Chi-square & $\chi^{2}=91.516$ & Probabilitas $\geq$ & Baik \\
& $\mathrm{P}=0.295$ & 0,05 & \\
GFI & 0.932 & GFI $>0.90$ & Baik \\
AGFI & 0.891 & AGFI $>0.90$ & Mendekati \\
TLI & 0.989 & TLI $>0.90$ & Baik \\
CFI & 0.992 & CFI $>0.90$ & Baik \\
RMSEA & 0.023 & RMSEA $\leq 0,08$ & Baik \\
\hline
\end{tabular}

Hasil pengujian SEM terhadap Indeks Goodness of fit model penelitian pada tabel diatas beberapa kriteria goodness of fit model diantaranya: nilai $\chi^{2}$ chi-square sebesar 91,516 dengan nilai Probabilitas 0,295 yang berarti lebih besar dari taraf signifikansi 0,05 (5\%), CMIN/DF sebesar 1,077; GFI sebesar 0,932 ;TLI sebesar
0,989; CFI sebesar 0,992; dan RMESA sebesar 0,023 .

\section{KESIMPULAN}

Berdasarkan dari data dan hasil analisismengenai keputusan pembelian secara online pada Toko Online yang ada dapat dilihat faktor-faktor apa saja yang mempengaruhi konsumen dalam melakukan keputusan pembelian, maka dapat ditarik kesimpulan sebagai berikut :

Dari hasil pengujian ini variabel program periklanan secara parsial berpengaruh positif dan signifikan terhadap variabel Pemprosesan Informasi. Hasil tersebut mengindikasikan bahwa semakin banyak kegiatan periklanan yang dilaksanakan maka informasi yang diberikan kepada konsumen akan semakin baik dan mudah diingat.

Dari hasil penelitian ini yang menunjukan bahwa para pengguna internet memproses informasi terutama sampai pada tingkatan kedua yakni tahap perhatian terhadap iklan yang diperolehnya. Hal ini sesuai dengan proses keputusan pembelian yang juga hanya sampai pada tahap perhatian pengguna internet terhadap iklan yang diperolehnya dengan melakukan klik atas iklan tersebut untuk mendapatkkan infomasi lebih lanjut sehingga konsumen bisa melakukan keputusan pembelian.

Dari hasil pengujian yang telah dilakukan menunjukkan bahwa variabel program periklanan dan kepercayaan konsumen melalui e-mail secara signifikan berpengaruh langsung ke keputusan pembelian atau tidak secara langsung dengan melalui pemprosesan informasi. Hal ini berarti bahwa keberhasilan keputusan pembelian yang dilakukan oleh pengguna internet dipengaruhi oleh variabel pemprosesan informasi.

\section{DAFTAR PUSTAKA}

1. Andam, Zorayda Ruth. May 2003.ECommerce and E-Business. e-ASEAN Task Force UNDP

2. Assauri, Sofyan. 2004. Manajemen Pemasaran (Dasar, Konsep, danStrategi). Jakarta : PT. Grafindo Persada 
3. Daryanto, 2003. Pengetahuan Dasar Ilmu Komputer. Bandung : YramaWidya

4. Dewanti, Retno. 2008 . Kewirausahaan . Jakarta : Mitra Wacana Media

5. Ferdinand, Agusty. 2002 Structural Equation Modelling dalam Penelitian Manajemen. Semarang : Badan Penerbit - UNDIP

6. Ghozali, Imam. 2005 Aplikasi Analisis Multivariat dengan Program SPSS Edisi 3. Badan Penerbit Universitas Diponegoro, Semarang

7. Kennedy, Jhon $\mathrm{E}$ dan $\mathrm{R}$ Dermawan Soemanagara. 2006. Marketing Communication Taktik \& Strategi. Jakarta : PT. Bhuana Ilmu Populer

8. Kotler, Philip. 2005. Manajemen Pemasaran. Jakarta : PT. INDEKS kelompok Gramedia

9. Mujiyana, 2011 Pengaruh Pelaksanaan Program Periklanan melalui Internet dan Pemasaran Melalui E-mail untuk Meningkatkan Pemasaran Produk UMKM di Wilayah Depok. Penelitian Hibah Bersaing Tahun Ketiga. Universitas Gunadarma. Jakarta. Indonesia

10.Randal, H, dan Latupile, C. 2005. Plug$N$-Play Internet.Indiana : Sam Publishing
11.Rosinta, Febrina dan Dwi Aryani. 2010. Pengaruh Kualitas Layanan terhadap Kepuasan Pelanggan dalam Membentuk Loyalitas Pelanggan. Jurnal Ilmu Administrasi dan Organisasi ,17(2), hal 114-126

12.Saladin, Djaslim. 2003. Manajemen Pemasaran.Bandung: Linda Karya

13. Sendjaja, Sasa Djuarsa. 2011. Proses Pembuatan Keputusan Konsumen Red Margo melalui Twitter. Jurnal Komunikasi. Vol 3 No 2

14. Setiawan, Ivan Aries dan Ferdiansyah Ritonga. 2011. Analisis Jalur (Path Analysis) dengan Menggunakan Program AMOS. Tanggerang : Suluh Media

15.Suhari, Yohanes. 2008. Keputusan Membeli Secara Online dan Faktorfaktor yang Mempengaruhinya. Jurnal Teknologi Informasi. Volume XIII, No.2, hal140-146

16.Suhari.2011. Kepercayaan Terhadap Internet Serta Pengaruhnya Pada Pencarian Informasi dan Keinginan Membeli Secara Online. Jurnal Dinamika Informatika. Vol 3 No 1

17.Suyanto, M. 2007. Marketing Strategy Top Brand Indonesia. Yogyakarta: ANDI

18.Swastha, Basu. 2004. Pengantar Bisnis Modern. Jakarta: Salemba Empat

19.www.apjii.or.id 